\title{
A facile approach to 2,2'-bipyridine based thiacrown ethers and their sulfoxides by DA-rDA reaction of 5,5'-bi-1,2,4-triazine thiamacrocycles. The conformation studies
}

\author{
Justyna Lawecka, Zbigniew Karczmarzyk,* Ewa Olender, Ewa Wolińska, Danuta \\ Branowska, and Andrzej Rykowski*
}

Siedlce University, Department of Chemistry, 08-110 Siedlce, Poland

E-mail: rykowski@ap.siedlce.pl

\begin{abstract}
Diels-Alder/retro Diels-Alder (DA-rDA) reactions of 5,5'-bi-1,2,4-triazine thiamacrocycles 4a-c afforded medium-size 2,2'-bipyridine based thiacrown ethers $\mathbf{5 a - c}$ in good yield. The latter were oxidized to non-racemic monosulfoxides 7a-c using Davis oxaziridine and tested as chiral auxilaries in the asymmetric addition of diethyl zinc to benzaldehyde. The theoretical calculations at DFT /B3LYP/6-311G** level were conducted thus establishing cis or trans conformational preferences of the target thiamacrocycles.
\end{abstract}

Keywords: Diels-Alder reaction, thiacrown ethers, bi-1,2,4-triazine, DFT calculations

\section{Introduction}

The macrocycles containing 2,2'-bipyridine (bpy) subunit have a wide range of applications in many areas of chemistry such as catalysis, metal extraction and molecular recognition. ${ }^{1}$ Moreover, $\mathrm{C}_{2}$-symmetric bpy crown-ethers have been developed recently for the enantioselective recognition of amino acids derivatives and chiral organic ammonium salts. ${ }^{2}$ Despite the vast knowledge on sulfur-metal interactions in coordination chemistry, ${ }^{3}$ the use of S-based ligands derived from bpy appeared to be still rather undeveloped. Such ligands should be able to coordinate to softer metal ions than those containing nitrogen or oxygen as donor atoms, and may constitute a valuable starting materials for the construction of more complex molecular and supramolecular systems. ${ }^{4}$ However, synthetic efforts in this area have been hampered by the lack of the efficient methods of their synthesis. ${ }^{5}$ In our preliminary work ${ }^{6}$ we have shown that $1,2,4$ triazine bis-sulfides, tethered to poly(ethylene glycol) chains undergo a remarkably facile, intramolecular cyclization into previously unknown 5,5'-bi-1,2,4-triazine thiacrown ethers (Scheme 1). The latter undergo an inverse electron demand Diels-Alder/retro Diels-Alder (DArDA) reaction with electron rich dienophiles affording bpy, or annulated bpy thiacrown ethers. ${ }^{6}$ 
From our preliminary findings and additional applications, ${ }^{7}$ one may assume that the approach is general one for the rings of 13 or more members. Here we would like to present a full account of this work on the synthesis of 16-, 19-, and 22- membered bpy thiacrown ethers and their conformational studies using the theoretical calculations. The obtained macrocycles were oxidized to non-racemic monosulfoxides by Davis oxaziridine ${ }^{8}$ and tested as chiral auxiliaries in an asymmetric addition of diethylzinc to benzaldehyde.

\section{Results and Discussion}

The starting 5,5'-bi-1,2,4-triazine thiacrown ethers 4a-c (Scheme 1) were readily prepared via three-step protocol described in our previous paper $^{7}$ which involved, (1) S-alkylation of thiosemicarbazide with the appropriate poly(ethylene glycol)dibromides 1a-c, (2) condensation of the resulting diquaternary salts $\mathbf{2 a - c}$ with glyoxal and, (3) intramolecular cyclization of such obtained 1,2,4-triazine bis-sulfides 3a-c with potassium cyanide under high dilution conditions. All steps of the synthesis involve inexpensive, commercially available starting materials and the thiacrown forming reactions can readily provide $69-77 \%$ yields of $\mathbf{4 a - c}{ }^{7}$
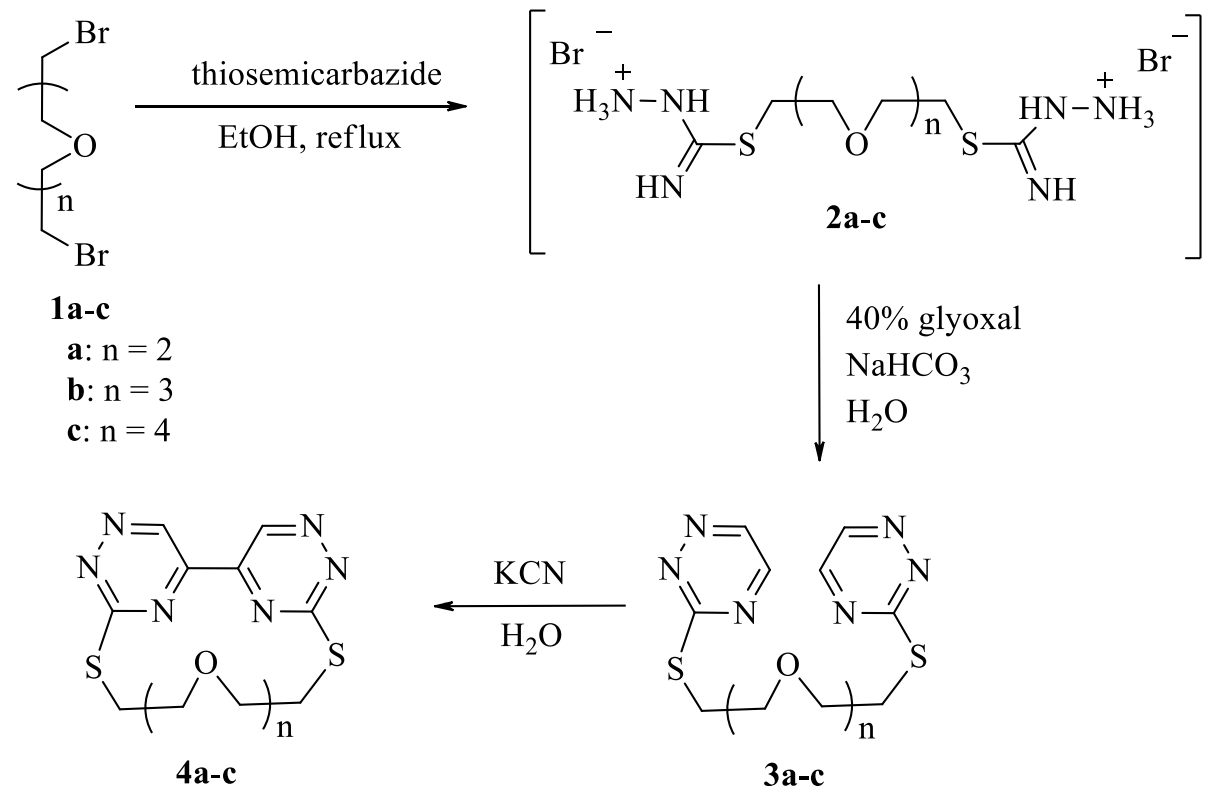

Scheme 1. Synthesis of cyclophanes $\mathbf{4 a - c}$.

The preparation of bpy thiacrown ethers $\mathbf{5 a}-\mathbf{c}$ could involve the DA-rDA reaction of $\mathbf{4 a - c}$ with appropriate dienophile (Scheme 2). 


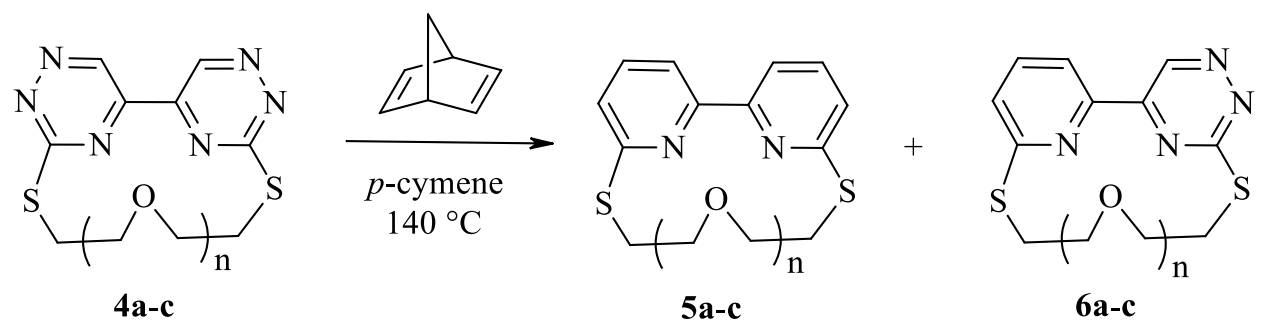

Scheme 2. Synthsis of cyclophanes $5 \mathbf{a}-\mathbf{c}$ and $\mathbf{6 a}-\mathbf{b}$.

Earlier, it was reported that DA-rDA reactions of 5,5'-bi-1,2,4-triazines with 2,5norbornadiene in boiling $p$-cymene led to $2,2^{\prime}$-bipyridine derivatives in good yields. ${ }^{9}$ However, this dienophile has never been used in the inverse electron demand DA-rDA reaction of 1,2,4triazine or bi-1,2,4-triazine based macrocycles. We initially attempted the DA-rDA reaction of 4a with 2,5-norbornadiene under the reaction conditions mentioned above, (method A), but in addition to the unreacted $\mathbf{4 a}$, the mixture was obtained containing, as its major component the expected bpy thiacrown ether 5a accompanied by some amounts of monoadduct $6 \mathbf{a}$ (Scheme 2). Attempts to increase cycloaddition yields failed, even when long times were used; compound $6 \mathbf{a}$ was still present in the reaction mixture. The similar mixture of products was obtained in reaction of compound $\mathbf{4 b}$ with 2,5-norbornadiene, (Scheme 2). The decrease in reactivity of $\mathbf{6 a}$ and $\mathbf{6 b}$ with 2,5-norbornadiene reflected the decreasing electron-withdrawing effect of pyridine ring in these heterocycles, as compared to starting bi-1,2,4-triazine 4a. However, when bi-1,2,4-triazine macrocycles 4a-c were reacted with 2,5- norbornadiene in a sealed Carius tube at elevated temperature under high pressure, $(\operatorname{method} \mathrm{B})$, the only products were the corresponding symmetrical derivatives $\mathbf{5 a}-\mathbf{c}$ obtained in good yields (Table 1). As the Diels-Alder reaction is know to posses a large negative volume of activation, thus action would serve to raise the ground-state energy of the reactants relative to the transition state, thereby lowering the activation energy. ${ }^{10}$ The spectroscopic properties of the bpy thiacrown ethers $\mathbf{5 a - c}$ are entirely consistent with the functional group present. The preferred conformations of these macrocycles are ascertained by the size of polythioetheral bridge and are determined by analyzing the chemical shifts of 3-pyridyl hydrogens. ${ }^{11}$ The resonances of such hydrogens in compounds $\mathbf{5 a}-\mathbf{b}$ (range from 7.46-7.59 ppm) indicate cis arrangement for these biheterocycles. In case of compound 5c $(\mathrm{n}=4)$ however, the chemical shift of $3-\mathrm{H}(\delta=8.02 \mathrm{ppm})$ shows a trans conformation for this pentethylene chain ligand. This is consistent with the chemical shifts of pyridine protons $(3 \mathrm{H}, \delta=8.11 \mathrm{ppm})$ in the parent $6,6^{\prime}$ - bis(ethylsulfanyl)-2,2'-bipyridine (Figure 1). ${ }^{12}$

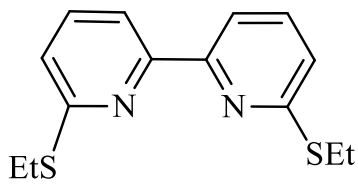

Figure 1. 6,6'- bis(ethylsulfanyl)- 2,2'-bipyridine. 
Table 1. Reaction conditions, yields and mp of compounds $5 \mathbf{a}-\mathbf{c}, \mathbf{6 a}-\mathbf{b}$ and $7 \mathbf{a}-\mathbf{c}$

\begin{tabular}{ccccc}
\hline Compound & Method & Time $(\mathrm{h})$ & Yield $(\%)$ & $\mathrm{Mp}\left({ }^{\circ} \mathrm{C}\right)$ \\
\hline $\mathbf{5 a}$ & $\mathrm{A}^{\mathrm{a}}$ & 20 & 31 & $82-83$ \\
$\mathbf{5 a}$ & $\mathrm{B}^{\mathrm{b}}$ & 45 & 78 & $82-83$ \\
$\mathbf{5 b}$ & $\mathrm{A}$ & 24 & 54 & $106-107$ \\
$\mathbf{5 b}$ & $\mathrm{B}$ & 64 & 70 & $106-107$ \\
$\mathbf{5 c}$ & $\mathrm{B}$ & 66 & 59 & $118-119$ \\
$\mathbf{6 a}$ & $\mathrm{A}$ & 20 & 6 & 140 \\
$\mathbf{6 b}$ & $\mathrm{A}$ & 24 & 10 & $138-139$ \\
$\mathbf{7 a}$ & - & 24 & 64 & oil \\
$\mathbf{7 b}$ & - & 24 & 71 & oil \\
$\mathbf{7 c}$ & - & 24 & 46 & oil \\
\hline
\end{tabular}

ain boiling $p$-cymene.

bin sealed Carius tube.

Moreover, these data also prove that twenty two-membered macrocyclic system $\mathbf{4 c}$ exists in trans conformation. In contrast, compounds $\mathbf{4 a}-\mathbf{b}$, containing sixteen and nineteen-membered macrocyclic rings exist in cis conformation exclusively. Finely, we have evaluated the asymmetric sulfoxidation of compounds $\mathbf{5 a}-\mathbf{c}$ using chiral oxaziridine developed by Davis. ${ }^{8}$ The reactions were performed in methylene chloride at room temperature (Scheme 3). Under these conditions the monosulfoxides $\mathbf{7 a - c}$ could be obtained in reasonable or good yield.

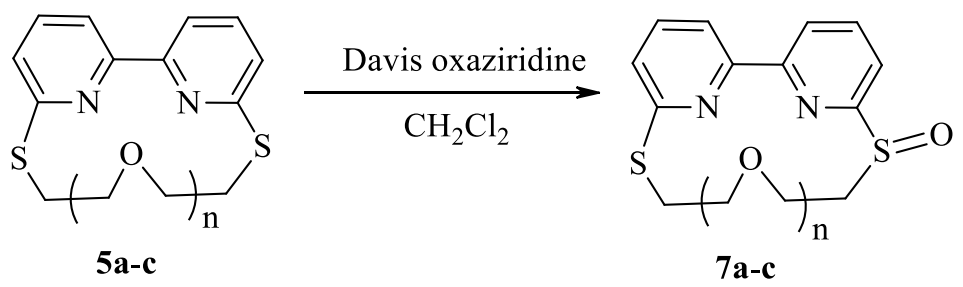

Scheme 3. Asymmetric sulfoxidation of cyclophanes 5a-c.

The preliminary use of these monosulfoxides as chiral auxilary was tested in asymmetric addition of the diethyl zinc to benzaldehyde, however their catalytic efficiency was poor and the ee values of the chiral alcohol thus obtained were much lower than the values observed for other catalysts. ${ }^{13}$

To establish the conformation preferences of 2,2'-bipyridine thiamacrocycles the theoretical calculations for 5a-c at DFT/B3LYP/6-311++G(d,p) level were undertaken. View of the molecules in conformation obtained after energy minimization and geometrical parameters optimization is shown in Figure 2. 

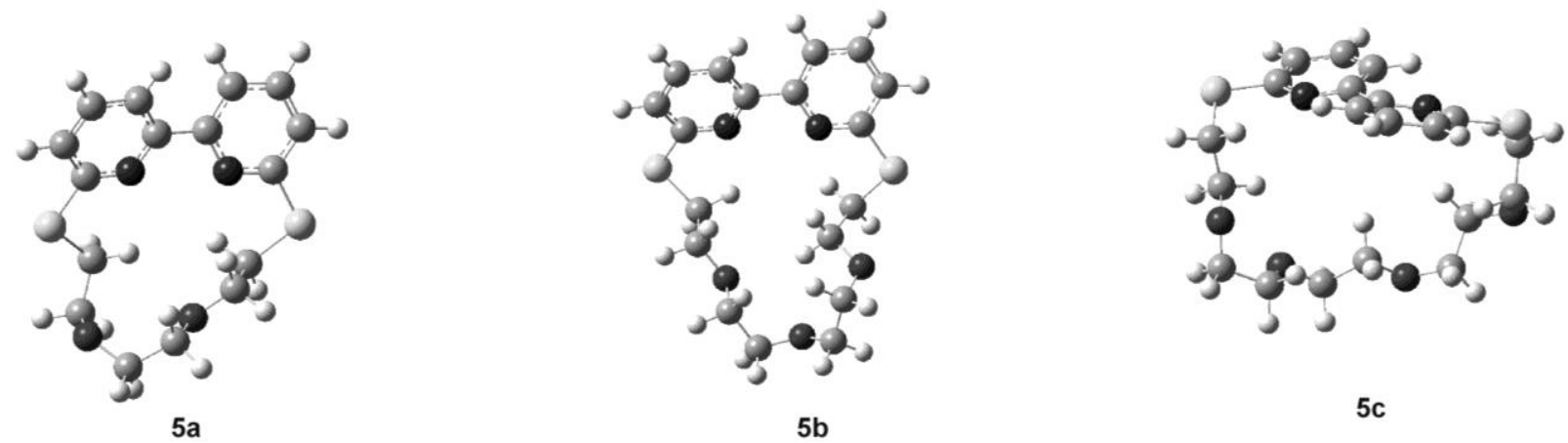

Figure 2. The molecular structures of 5a-c obtained from DFT/B3LYP/6-311++G(d,p) calculations.

The molecules 5a and $\mathbf{5 b}$ containing respectively sixteen- and nineteen-membered macrocyclic ring adopt the cis (syn) conformation with the torsion angle $\varphi=$ N1-C2-C2'-N2' about the central bond of the bipyridyl system of $-23.5^{\circ}$ for $\mathbf{5 a}$ and 15.10 for $\mathbf{5 b}$. In the molecule 5c with twenty two-membered macrocyclic system the bipyridyl group is in trans (anti) conformation with the torsion angle of $163.4^{\circ}$. The calculated conformations of 2,2'-bipyridine systems in $\mathbf{5 a}-\mathbf{c}$ are very similar to those obtained from X-ray analysis of structurally related annulated 2,2'-bipyridine thiamacrocycles. ${ }^{7}$ In the case of $\mathbf{5 a}$ the cis conformation is forced by the strain effect in the twelve-membered thiaethereal chain during the cyclization process. The elongation of the thiaethereal chain in $\mathbf{5 b}$ and $\mathbf{5 c}$ can give the possibility to change the mutual orientation of pyridine rings. The energy effects of the free rotation between the pyridine rings, taking into account the one degree of freedom described by torsion angle $\varphi$, were calculated for $\mathbf{5 b}$ and $\mathbf{5 c}$ using the AM1 method. The differences in heat of formation, $\Delta \mathrm{HF}$, of the conformations were calculated after minimization and all geometrical parameters optimization for each rotation, with a $10^{\circ}$ increment from -180 to $180^{\circ}$ of $\varphi$ (Figure 3). The calculated conformations with minima of energy are in good agreement with those calculated at $a b$ initio DFT level and those observed in the crystalline state of respective annulated 2,2'-bipyridine thiamacrocycles structurally related to $\mathbf{5 b}$ and $\mathbf{5 c}$. The energy difference between conformers in maximum (trans) and minimum (cis) of energy in $\mathbf{5 b}$ is $\sim 14.9 \mathrm{kcal} / \mathrm{mol}$. This barrier of energy can inhibit the free rotation at $\mathrm{C} 2-\mathrm{C} 2$ ' central bond and can prevent the 2,2'-bipyridyl group changing the cis conformation in room temperature. The energy differences between rotamers of $\mathbf{5 c}$, of about $6.6 \mathrm{kcal} / \mathrm{mol}$, are relatively lower and the tendency in the energy minima distribution to gauche and trans conformations is good visible. One should notice, that the polarization vectors of $\mathrm{N} 1-\mathrm{C} 2$ and $\mathrm{N} 1$ '-C2' bonds (as well as $\mathrm{C} 2-\mathrm{C} 3$ and $\mathrm{C} 2$ '-C3' bonds) in pyridine rings are in the most profitable anti-parallel position in trans conformation of 2,2'-bipyridyl system. The existence of this electronic effect is confirmed by the charge distribution at N1 $(-0.505 e)$, $\mathrm{C} 2(+0.184 e), \mathrm{N} 1{ }^{\prime}(-0.508 e)$ and $\mathrm{C}^{\prime}{ }^{\prime}(+0.193 e)$ atoms obtained for 5c from natural bond order (NBO) analysis at DFT/B3LYP/6-311++G9d,p) level. The similar values of charges are also 
observed at $\mathrm{N} 1, \mathrm{C} 2, \mathrm{~N} 1$ ' and $\mathrm{C} 2$ ' atoms of $-0.488 e,+0.183 e,-0.460 e$ and $+0.207 e$, respectively for $\mathbf{5 a}$, and $-0.478 e,+0.199 e,-0.489 e$ and $+0.185 e$, respectively for $\mathbf{5 b}$, but the $c i s$ conformation of 2,2'-bipyridyl system in these molecules is the resultant effect of electrostatic dipole-dipole interaction, steric and strain effects in thiaetheral chain, with the predomination of the later. Theoretical calculations showed, that the $\mathrm{C}_{2}$ symmetry of macrocycles $\mathbf{5 a}-\mathbf{c}$ is not retained and the conformations of the left and right parts of molecules (cis-trans-gauche-gauchegauche-gauche and cis-gauche-trans-trans-trans-gauche in 5a, cis-gauche-gauche-transgauche-gauche-gauche and cis-gauche-trans-trans-trans-gauche-gauche in $\mathbf{5 b}$ and cis-gauchetrans-trans-gauche-gauche-trans-gauche-trans and cis-gauche-trans-gauche-gauche-transgauche-trans-trans in 5c) are somewhat different, similarly as in the case of annulated 2,2'bipyridine thiamacrocycles.

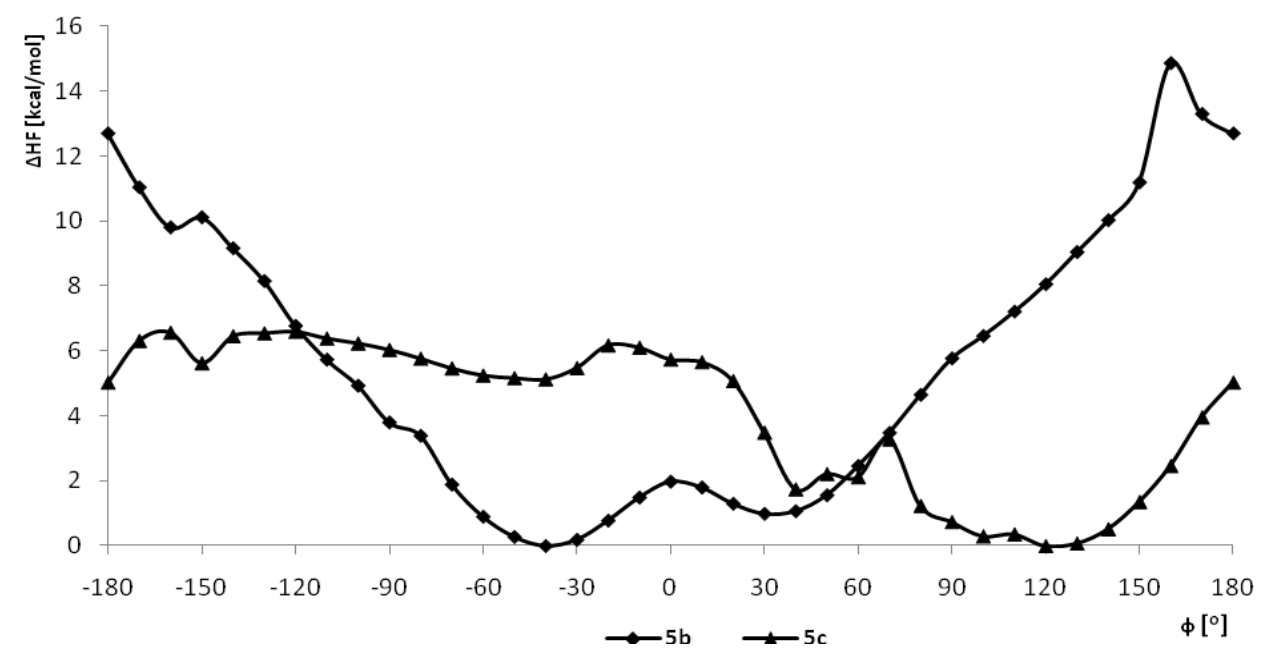

Figure 3. The energy effect upon C2-C2' $(\varphi)$ rotation for $\mathbf{5 b}$ and $\mathbf{5 c}$ using AM1 semiempirical method.

\section{Conclusions}

We have demonstrated a facile approach to 2,2'-bipyridine thiacrown ethers. The preferred conformations of these macrocycles are ascertained by the size of polyetheral bridge and can be determined by ${ }^{1} \mathrm{H}$ NMR and the theoretical calculations at the DFT level. Further studies on application of the obtained macrocycles as complexing agents are in progress.

\section{Experimental Section}

General. Melting points are uncorrected. ${ }^{1} \mathrm{H}$ and ${ }^{13} \mathrm{C}$ NMR spectra were determined at 200 and $50 \mathrm{MHz}$, respectively, with a Varian Gemini spectrometer. Chemical shifts $(\delta)$ are given in parts per million and coupling constants are given as absolute values expressed in Hertz. Mass spectra 
were obtained by using AMD 604 (AMD Intectra GmbH, Germany) and GC/MS QP 5050 Shimadzu (30 m $\times 0.25 \mathrm{~mm}$ ID-BPX $50.25 \mathrm{~mm})$ spectrometers. Elemental analyses were recorded with a Perkin-Elmer 2400-CHN analyzer and the results for indicated elements were within $0.3 \%$ of the calculated values. Optical rotation values were measured at room temperature with a JASCO P-2000 polarimeter. The ee values were determined by HPLC analysis by using a chiral stationary phase column (chirobiotic T). Thin layer chromatography (TLC) was carried out on aluminium sheets percolated with silica gel $60 \mathrm{~F}_{254}$ (Merck). Column chromatography separations were performed by using Merck Kieselgel $60(0.040-0.060 \mathrm{~mm})$. Solvents were dried and distilled according to standard procedures. Syntheses of 1,8-bis(1,2,4-triazin-3-ylsulfanyl)3,6-dioxaoctane 3a, 1,11-bis(1,2,4-triazin-3-ylsulfanyl)-3,6,9-trioxaundecane 3b, 1,14-bis(1,2,4triazin-3-ylsulfanyl)-3,6,9,12-tetraoxatetradecane $\quad 3 c$, 4,7-dioxa-1,10-dithia[10]3,3'-5,5'bis(1,2,4-triazin-3-ylsulfanyl)cyclophane $\quad \mathbf{4 a}, \quad 4,7,10$-trioxa-1,13-dithia[13]3,3'-5,5'-bis(1,2,4triazin-3-ylsulfanyl)cyclophane $\mathbf{4 b}, 4,7,10,13$-tetraoxa-1,16-dithia[16]3,3'-5,5'-bis(1,2,4-triazin3-ylsulfanyl)cyclophane $\mathbf{4 c}$ were performed according to our published procedures. ${ }^{6,7}$

\section{General procedure for the preparation of thiacrown ethers $(5 a-c)$ and $(6 \mathbf{a}-\mathbf{b})$}

Method A. A solution of 2,5-norbornadiene (1.8 ml) in p-cymene (4 ml) containing compounds 4a-b $(0.59 \mathrm{mmol}$ ) was heated for $20-24 \mathrm{~h}$ (see Table 1$)$ at $140{ }^{\circ} \mathrm{C}$. The solvent was evaporated in vacuo and the mixture was separated by column chromatography on silica gel, using dichloromethane/acetone (20:1) to give compounds $\mathbf{5 a}-\mathbf{b}$, followed by dichloromethane/acetone (10:1) to afford monoadducts $\mathbf{6 a}-\mathbf{b}$.

Method B. A solution of 2,5-norbornadiene $(1.8 \mathrm{ml})$ in $p$-cymene $(4 \mathrm{ml})$ was added to a Carius tube containing $4 \mathbf{a}-\mathbf{c}(0.59 \mathrm{mmol})$. The tube was tightly closed and the mixture was heated for $45-66 \mathrm{~h}$ as indicated in Table 1 at $140{ }^{\circ} \mathrm{C}$. The solvent was evaporated in vacuo and the product was purified by column chromatography on silica gel, using dichloromethane/acetone (20:1) as eluent to give pure compounds $\mathbf{5 a}-\mathbf{c}$.

4,7-dioxa-1,10-dithia[10](6,6')-2,2'-bis(pyridine)cyclophane (5a). Method A. $61 \mathrm{mg}, 31 \%$; Method B. $153 \mathrm{mg}, 78 \%$; white crystals; mp 82-83 ${ }^{\circ} \mathrm{C}$ (lit. ${ }^{6} \mathrm{mp} 82-83{ }^{\circ} \mathrm{C}$ ).

4,7,10-trioxa-1,13-dithia[13](6,6')-2,2'-bis(pyridine)cyclophane (5b). Method A: $132 \mathrm{mg}$, 54\%; Method B: $156 \mathrm{mg}, 70 \%$; 106-107 ${ }^{\circ} \mathrm{C}$; ${ }^{1} \mathrm{H}$ NMR (200 MHz, $\left.\mathrm{CDCl}_{3}\right) \delta 3.34-3.37$ (m, 4H, $\left.\mathrm{SCH}_{2}\right), 3.49-3.61\left(\mathrm{~m}, 8 \mathrm{H}, \mathrm{OCH}_{2}\right), 3.78\left(\mathrm{t}, J=6.9 \mathrm{~Hz}, 4 \mathrm{H}, \mathrm{OCH}_{2}\right), 7.24(\mathrm{~d}, J=7.2 \mathrm{~Hz}, 2 \mathrm{H}$, pyridine hydrogen atoms), 7.57-7.62 (m, 4H, pyridine hydrogen atoms); ${ }^{13} \mathrm{C} \mathrm{NMR}(50 \mathrm{MHz}$, $\left.\mathrm{CDCl}_{3}\right) \delta 29.3\left(\mathrm{SCH}_{2}\right), 69.7\left(\mathrm{OCH}_{2}\right), 70.8\left(\mathrm{OCH}_{2}\right), 71.1\left(\mathrm{OCH}_{2}\right), 117.8,122.8,136.4,156.2$, 158.0 pyridine carbon atoms. Anal. Calcd for $\mathrm{C}_{18} \mathrm{H}_{22} \mathrm{~N}_{2} \mathrm{O}_{3} \mathrm{~S}_{2}$ : C, 57.14; H, 5.82; N, 7.41. Found: C, 56.99; H, 5.80; N, 7.26.

4,7,10,-tetraoxa-1,16-dithia[16](6,6')-2,2'-bis(pyridine)cyclophane (5c). Method B. $132 \mathrm{mg}$, 75\%; mp 63-64 ${ }^{\circ} \mathrm{C} ;{ }^{1} \mathrm{H}$ NMR (200 $\left.\mathrm{MHz} \mathrm{CDCl}_{3}\right) \delta 3.07$ (s, 2H, $\mathrm{CH}_{2}$ ), 3.32-3.37 (m, 4H, $\mathrm{CH}_{2}$ ), 3.49-3.56 (m, 8H, $\left.\mathrm{OCH}_{2}\right), 3.76\left(\mathrm{t}, J=6.4 \mathrm{~Hz}, 4 \mathrm{H}, \mathrm{OCH}_{2}\right), 7.23(\mathrm{~d}, J=8.4 \mathrm{~Hz}, 2 \mathrm{H}$, pyridine hydrogen atoms), $7.58(\mathrm{~d}, J=7.8 \mathrm{~Hz}, 2 \mathrm{H}$, pyridine hydrogen atoms) $8.02(\mathrm{~d}, J=7.6 \mathrm{~Hz}, 2 \mathrm{H}$, pyridine hydrogen atoms); ${ }^{13} \mathrm{C} \mathrm{NMR}\left(50 \mathrm{MHz}, \mathrm{CDCl}_{3}\right) \delta 29.2\left(\mathrm{SCH}_{2}\right), 70.1\left(\mathrm{OCH}_{2}\right), 70.2$ 
$\left(\mathrm{OCH}_{2}\right), 70.5\left(\mathrm{OCH}_{2}\right), 71.2\left(\mathrm{OCH}_{2}\right), 117.0,122.9,136.6,155.3,157.4$ pyridine carbon atoms. HRMS (EI) calcd for $\mathrm{C}_{20} \mathrm{H}_{26} \mathrm{~N}_{2} \mathrm{O}_{4} \mathrm{~S}_{2}$ : 422.13340; found: 422.13504.

\section{0,13-Dioxa-7,16-dithia-4,5,21,22-tetraaza-tricyclo[15.3.1.1 $\left.{ }^{2,6}\right]$ docosa-1(21),2(22),3,17,19-}

hexaene (6a). Method A. $12 \mathrm{mg}, 6 \%$; mp $140{ }^{\circ} \mathrm{C}$; ${ }^{1} \mathrm{H}$ NMR $\left(200 \mathrm{MHz}, \mathrm{CDCl}_{3}\right) \delta$ 3.47-3.62 (m, $\left.4 \mathrm{H}, 2 \mathrm{xCH}_{2}\right), 3.68\left(\mathrm{~s}, 4 \mathrm{H}, 2 \mathrm{xCH}_{2}\right), 3.75-3.93\left(\mathrm{~m}, 4 \mathrm{H}, 2 \mathrm{xCH}_{2}\right), 7.23(\mathrm{dd}, 1 \mathrm{H}, J=2.2,6.6 \mathrm{~Hz}$, pyridine hydrogen atoms), 7.64-7.71 $(\mathrm{m}, 2 \mathrm{H}$, pyridine hydrogen atoms) $9.36(\mathrm{~s}, 1 \mathrm{H}$, triazine hydrogen atom); ${ }^{13} \mathrm{C}$ NMR $\left(50 \mathrm{MHz}, \mathrm{CDCl}_{3}\right) \delta 28.6\left(\mathrm{SCH}_{2}\right), 29.2\left(\mathrm{SCH}_{2}\right), 69.6\left(\mathrm{OCH}_{2}\right), 69.9$ $\left(\mathrm{OCH}_{2}\right), 70.5\left(\mathrm{OCH}_{2}\right), 70.6\left(\mathrm{OCH}_{2}\right), 119.3,125.2,136.6,142.5,150.8,154.0,160.8$ pyridine carbon atoms, 174.6 triazine carbon atoms. HRMS (EI) calcd for $\mathrm{C}_{14} \mathrm{H}_{16} \mathrm{~N}_{4} \mathrm{O}_{2} \mathrm{~S}_{2}$ : 336.07147 ; found: 336.07138 .

\section{0,13,16-Trioxa-7,19-dithia-4,5,24,25-tetraaza-tricyclo[18.3.1.1 $\left.{ }^{2,6}\right]$ pentacosa-}

1(24),2(25),3,20,22-hexaene (6b). Method A. $22 \mathrm{mg}, 10 \%$; mp 138-139 ${ }^{\circ} \mathrm{C} ;{ }^{1} \mathrm{H} \mathrm{NMR}(200 \mathrm{MHz}$, $\left.\mathrm{CDCl}_{3}\right) \delta$ 3.33-3.49 (m, 4H, $\left.\mathrm{CH}_{2}\right), 3.50-3.61$ (m, 8H, $\left.\mathrm{OCH}_{2}\right), 3.72-3.84$ (m, 4H, $\mathrm{OCH}_{2}$ ), 7.38 (dd, $1 \mathrm{H}, J=0.9,7.9 \mathrm{~Hz}$, pyridine hydrogen atom), $7.68(\mathrm{t}, 1 \mathrm{H}, J=7.6 \mathrm{~Hz}$, pyridine hydrogen atom), 7.79 (dd, $1 \mathrm{H}, J=1.0,8.1 \mathrm{~Hz}$, pyridine hydrogen atom), $9.56\left(\mathrm{~s}, 1 \mathrm{H}\right.$, triazine hydrogen atom), ${ }^{13}$ C NMR $\left(50 \mathrm{MHz}, \mathrm{CDCl}_{3}\right) \delta 28.6\left(\mathrm{SCH}_{2}\right), 30.6\left(\mathrm{SCH}_{2}\right), 69.4\left(\mathrm{OCH}_{2}\right), 70.4\left(\mathrm{OCH}_{2}\right), 70.6$ $\left(\mathrm{OCH}_{2}\right), 70.7\left(\mathrm{OCH}_{2}\right), 70.8\left(\mathrm{OCH}_{2}\right), 71.0\left(\mathrm{OCH}_{2}\right), 118.9,125.3,128.8,136.8,142.9,151.2$, 153.8 pyridine carbon atoms, 159.8 triazine carbon atoms. HRMS (EI) calcd for $\mathrm{C}_{16} \mathrm{H}_{20} \mathrm{~N}_{4} \mathrm{O}_{3} \mathrm{~S}_{2}$ : 380.09768; found: 380.09817 .

\section{General procedure for the preparation of sulfoxides $(7 \mathbf{a}-\mathbf{c})$ (Davis method)}

To a solution of the sulfide $\mathbf{5 a}-\mathbf{c}(1 \mathrm{mmol})$ in anhydrous methylene chloride $(30 \mathrm{ml}),(+)-\left(8,8^{\prime}-\right.$ dichlorocamphorylsulfonyl)oxaziridine $(0.75 \mathrm{mmol})$ was added and the reaction mixture was stirred at room temperature for $24 \mathrm{~h}$. Afterwards, the solvent was evaporated and the residue was purified by flash chromatography using $\mathrm{CH}_{2} \mathrm{Cl}_{2}$-acetone $(10: 1.5)$ as eluent to yield pure monosulfoxides $\mathbf{6 a}-\mathbf{c}$.

4,7-Dioxa-1,10-dithia[10](6,6')-2,2'-bis(pyridine) sulfoxide (7a). $224 \mathrm{mg}$, 64\%; oil ; ee 22\%, $[\alpha]_{\mathrm{D}}{ }^{20}=-32\left(c 1.0, \mathrm{CH}_{2} \mathrm{Cl}_{2}\right) .{ }^{1} \mathrm{H}$ NMR $\left(200 \mathrm{MHz}, \mathrm{CDCl}_{3}\right) \delta 3.08-3.38\left(\mathrm{~m}, 2 \mathrm{H}, \mathrm{OCH}_{2}\right), 3.50-3.67$ $\left(\mathrm{m}, 5 \mathrm{H}, \mathrm{OCH}_{2}\right), 3.74-4.13\left(\mathrm{~m}, 4 \mathrm{H}, \mathrm{OCH}_{2}\right), 4.16-4.27(\mathrm{~m}, 1 \mathrm{H}), 7.22(\mathrm{~d}, J=7.7 \mathrm{~Hz}, 1 \mathrm{H}$, pyridine hydrogen atom), $7.49(\mathrm{~d}, J=7.4 \mathrm{~Hz}, 1 \mathrm{H}$, pyridine hydrogen atom), $7.58(\mathrm{t}, J=7.6 \mathrm{~Hz}, 1 \mathrm{H}$, pyridine hydrogen atom) 7.77-7.84 (m, $1 \mathrm{H}$, pyridine hydrogen atom), 7.98-8.07 (m, 2H, pyridine hydrogen atoms); ${ }^{13} \mathrm{C} \mathrm{NMR}\left(50 \mathrm{MHz}, \mathrm{CDCl}_{3}\right) \delta 27.7\left(\mathrm{SCH}_{2}\right), 57.1\left(\mathrm{SOCH}_{2}\right), 64.8\left(\mathrm{OCH}_{2}\right), 70.1-$ 71.2 (3C overlapped, $\mathrm{OCH}_{2}$ ), 117.6, 119.0, 122.3, 122.4, 136.6, 138.5, 154.9, 156.3, 158.5, 166.0 pyridine carbon atoms. HRMS (EI) calcd for $\mathrm{C}_{16} \mathrm{H}_{18} \mathrm{~N}_{2} \mathrm{O}_{3} \mathrm{~S}_{2}$ : 350.07588; found: 350.07552 .

4,7,10-Trioxa-1,13-dithia[13](6,6')-2,2'-bis(pyridine) sulfoxide (7b). $278 \mathrm{mg}$, 71\%; oil; ee $61 \%,[\alpha]_{\mathrm{D}}^{20}=-172\left(c 1.0, \mathrm{CH}_{2} \mathrm{Cl}_{2}\right) .{ }^{1} \mathrm{H} \mathrm{NMR}\left(200 \mathrm{MHz}, \mathrm{CDCl}_{3}\right) \delta 2.86-3.62\left(\mathrm{~m}, 13 \mathrm{H}, \mathrm{OCH}_{2}\right)$, 3.71-3.78 (m, $\left.1 \mathrm{H}, \mathrm{OCH}_{2}\right), 3.96-4.22\left(\mathrm{~m}, 2 \mathrm{H}, \mathrm{OCH}_{2}\right), 7.24(\mathrm{~d}, J=7.8 \mathrm{~Hz}, 1 \mathrm{H}$, pyridine hydrogen atom), 7.61 (t, $J=7.7 \mathrm{~Hz}, 1 \mathrm{H}$, pyridine hydrogen atom), $7.87(\mathrm{~d}, J=7.6 \mathrm{~Hz}, 1 \mathrm{H}$, pyridine hydrogen atom), 7.96-8.05 (m, 2H, pyridine hydrogen atom), 8.24-8.33 (m, 1H, pyridine hydrogen atoms); ${ }^{13} \mathrm{C}$ NMR $\left(50 \mathrm{MHz}, \mathrm{CDCl}_{3}\right) \delta 28.1\left(\mathrm{SCH}_{2}\right), 51.8\left(\mathrm{SOCH}_{2}\right), 60.5\left(\mathrm{OCH}_{2}\right), 69.3$ 
$\left(\mathrm{OCH}_{2}\right), 69.7\left(\mathrm{OCH}_{2}\right), 70.2\left(\mathrm{OCH}_{2}\right), 70.3\left(\mathrm{OCH}_{2}\right), 70.7\left(\mathrm{OCH}_{2}\right), 117.5,119.5,122.1,123.4$, 136.8, 137.9, 154.9, 156.1, 157.1, 163.8 pyridine carbon atoms. HRMS (EI) calcd for $\mathrm{C}_{18} \mathrm{H}_{22} \mathrm{~N}_{2} \mathrm{O}_{4} \mathrm{~S}_{2}$ : 394.10210; found: 394.10202.

4,7,10,13-Tetraoxa-1,16-dithia[16](6,6')-2,2'-bis(pyridine) sulfoxide (7c). $201 \mathrm{mg}$, 46\%; oil; ee $33 \%,[\alpha]_{\mathrm{D}}{ }^{20}=-137\left(c 1.0, \mathrm{CH}_{2} \mathrm{Cl}_{2}\right)$. ${ }^{1} \mathrm{H} \mathrm{NMR}\left(200 \mathrm{MHz}, \mathrm{CDCl}_{3}\right) \delta 2.92-3.90(\mathrm{~m}, 18 \mathrm{H}$, $\left.\mathrm{OCH}_{2}\right), 4.03-4.16\left(\mathrm{~m}, 2 \mathrm{H}, \mathrm{OCH}_{2}\right), 7.26(\mathrm{~d}, J=8.0 \mathrm{~Hz}, 1 \mathrm{H}$, pyridine hydrogen atom $), 7.23(\mathrm{t}, J=$ $7.9 \mathrm{~Hz}, 1 \mathrm{H}$, pyridine hydrogen atom), 7.96-8.09 (m, 3H, pyridine hydrogen atom), 8.42-8.53 (m, $1 \mathrm{H}$, pyridine hydrogen atoms); ${ }^{13} \mathrm{C}$ NMR $\left(50 \mathrm{MHz}, \mathrm{CDCl}_{3}\right) \delta 27.8\left(\mathrm{SCH}_{2}\right), 49.4\left(\mathrm{SOCH}_{2}\right), 59.3$ $\left(\mathrm{OCH}_{2}\right)$, 68.9-69.8 (6C overlapped, $\left.\mathrm{OCH}_{2}\right), 115.6,118.7,120.0,122.1,135.5,136.7,153.0$, 154.2, 156.3, 162.9 pyridine carbon atoms. HRMS (EI) calcd for $\mathrm{C}_{20} \mathrm{H}_{26} \mathrm{~N}_{2} \mathrm{O}_{5} \mathrm{~S}_{2}$ : 438.12831; found: 438.12754 .

\section{Theoretical calculations}

The energy, geometrical parameters (bond lengths, angles and torsion angles) and charge distribution on the atoms for structures $\mathbf{5 a}, \mathbf{5 b}$ and $\mathbf{5 c}$ were calculated with GAUSSIAN $03^{14}$ at the DFT/B3LYP level with 6-311++G(d,p) basis set. The structures were fully optimized without

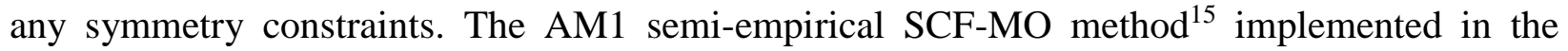
program package WINMOPAC ${ }^{16}$ were undertaken to investigate the conformational preferences of 2,2'-bipyridine system of the investigated molecules.

\section{References}

1. (a) Kaes, C.; Katz, A.; Hoseini, M. N. Chem. Rev. 2000, 100, 3553. (b) Cago S.; Pilinger, M.; Valente, A. A.; Santos, T. M.; Rocha, J.; Goncalves, I. S. Innorg. Chem. 2004, 43, 5422. (c) Van Veggel, F. C. J. M.; Verboom, N.; Reinhoudt, D. N. Chem.Rev. 1994, 94, 279. (d) Stevens, A. C.; Freiser, H. Anal. Chim. Acta 1991, 248, 315. (e) Durr, H.; Bossmann, S. H. Acc. Chem. Res. 2001, 34, 905. (f) Ha, J.-Z.; Bossmann, S. H.; Van Loyen, D.; Schwarz, O.; Durr, H. Chem. Eur. J. 1999, 5, 1267. (g) Bossmann, S. H.; Durrer, H.; Pokhrel, M. R. Synthesis 2005, 907 and references cited therein.

2. Lee, C.-S.; Teng, P.-F.; Wong, W.-1.; Kwong, H.-1.; Chan, A. S. C. Tetrahedron 2005, 61, 7924.

3. Murray, S. G.; Hartley, F. R. Chem. Rev. 1981, 81, 365.

4. Lehn, J.-M. Supramolecular Chemistry, Concepts and Perspectives; VCH: Weinheim, 1995.

5. Buhleier, E.; Vögtle, F. Liebigs Ann. Chem. 1977, 1080.

6. Ławecka, J.; Olender, E.; Piszcz, P.; Rykowski, A. Tetrahedron Lett. 2008, 49, 723.

7. Ławecka, J.; Karczmarzyk, Z.; Wolińska, E.; Branowska, D.; Rykowski, A. Eur. J. Org. Chem. 2010, DOI:10.1002/ejoc.201000590.

8. Davis, F. A.; Reddy, T. R.; Weismiller, M. C. J. J. Am. Chem. Soc., 1989, 111, 5964.

9. Branowska, D. Molecules 2005, 10, 265. 
10. Grieco, P. A.; Nunes, J. J.; Gaul, M. D. J. Am. Chem. Soc. 1990, 112, 4596.

11. Newkome, G. R.; Nayak, A.; Fronczek, F.; Kawato, T.; Taylor, H. C. R.; Meade, L.; Mattice, W. J. Am. Chem. Soc. 1978, 101, 4472.

12. Branowska, D. Synthesis 2003, 2096.

13. Noyori, R.; Kitamura, M. Angew. Chem. Int. Ed. Engl. 1991, 30, 49.

14. Frisch, M. J.; Trucks, G. W.; Schlegel, H. B.; Scuseria, G. E.; Robb, M. A.; Cheeseman, J. R.; Montgomery, Jr., J. A.; Vreven, T.; Kudin, K. N.; Burant, J. C.; Millam, J. M.; Iyengar, S. S.; Tomasi, J.; Barone, V.; Mennucci, B.; Cossi, M.; Scalmani, G.; Rega, N.; Petersson, G. A.; Nakatsuji, H.; Hada, M.; Ehara, M.; Toyota, K.; Fukuda, R.; Hasegawa, J.; Ishida, M.; Nakajima, T.; Honda, Y.; Kitao, O.; Nakai, H.; Klene, M.; Li, X.; Knox, J. E.; Hratchian, H. P.; Cross, J. B.; Bakken, V.; Adamo, C.; Jaramillo, J.; Gomperts, R.; Stratmann, R. E.; Yazyev, O.; Austin, A. J.; Cammi, R.; Pomelli, C.; Ochterski, J. W.; Ayala, P. Y.; Morokuma, K.; Voth, G. A.; Salvador, P.; Dannenberg, J. J.; Zakrzewski, V. G.; Dapprich, S.; Daniels, A. D.; Strain, M. C.; Farkas, O.; Malick, D. K.; Rabuck, A. D.; Raghavachari, K.; Foresman, J. B.; Ortiz, J. V.; Cui, Q.; Baboul, A. G.; Clifford, S.; . Cioslowski, J.; Stefanov, B. B.; Liu, G.; Liashenko, A.; Piskorz, P.; Komaromi, I.; Martin, R. L.; Fox, D. J.; Keith, T.; Al-Laham, M. A.; Peng, C. Y.; Nanayakkara, A.; Challacombe, M.; Gill, P. M. W.; Johnson, B.; Chen, W.; Wong, M. W.; Gonzalez, C.; Pople, J. A., Gaussian 03, Revision E.01, Gaussian, Inc., Wallingford CT, 2004.

15. Dewar, M. J. S.; Zoebish, E. G.; Healy, E.F.; Stewart, J. P. J. Am. Chem. Soc. 1985, 107, 3902.

16. Scchepin, R; Litvinov, D., WINMOPAC, Version 7.21, Perm State University, Perm, Russia, 1998. Available from: http://www.psu.ru/science/soft/winmopac/index_e.html 